\title{
Young siblings of children with cancer deserve personalized care
}

Volume 7 Issue 3 - 2017

\section{Case report}

The onset of a life-threatening disease in a child is an event that has a profound impact on the specific child/family relationship. The family becomes a recipient for the stress related to the illness, and takes on the greatest responsibility for the child's psychosocial adjustment.

This kind of diagnosis poses a threat to the whole family unit, mostly to parents and siblings. The impact of the diagnosis and coping style must always be taken into consideration from the beginning. ${ }^{1}$ Parents and especially mothers are reported as being the main source of support both for all aged children and for adolescent patients.,3 Even if most data on parental adjustment is based on mothers, also fathers have been shown to exhibit significant distress. ${ }^{4}$

On several occasions parents are asked to carry out various aspects of disease management and therapy at home, including drug administration, catheter up-keep, mouth washes to prevent mucositis, and monitoring the child's reactions to therapy. This involvement may be perceived as a great responsibility, and the caregivers may feel alone because they do not recognize enough support from their partners. ${ }^{5}$ Several Authors have emphasized the importance of starting psychological support as soon as possible during the period of diagnosis. ${ }^{6}$ Childhood cancer and its invasive treatment are the source of both practical and emotional stress for all family members, and not only for the patient. ${ }^{7}$ High levels of parental distress have been found in many studies, ${ }^{8}$ both at the time of diagnosis and in the early stages of treatment, and they may persist up to five years post diagnosis. ${ }^{9}$

Therefore the families of children with cancer focus their care mostly on the sick child throughout the whole period of the care, which very often means several years.

When a child is diagnosed with cancer, siblings face significant disruption in their lives and in their sense of self. ${ }^{10}$ Despite the attention given to the siblings adaptation and coping style they are still labeled the "forgotten children". ${ }^{11}$ They experience significant psychosocial distress and are often isolated from support systems within and without their family. Several factors influence the siblings' outcome like age gender, family functioning and coping.

As reported in Standard care in Pediatric Oncology, "Siblings of children with cancer are a psychosocially at risk group and should be provided with appropriate supportive services. Parents and professionals should be advised about ways to anticipate and meet siblings' needs, especially when siblings are unable to visit the hospital regularly". ${ }^{12}$

Often, healthy siblings undergo feelings of loss, fear, suffering, uncertainty, loneliness, jealousy, anger and guilt. ${ }^{13-16}$ Woodgate $^{16}$ during an interview to siblings of patient with cancer found an "enduring sadness" that didn't have a clinical relevance ${ }^{17}$ but it is a predisposing factor to the development of anxiety and depression, which are disorders more frequent in this sample. ${ }^{18}$ Not only did the

\author{
Caprino D, Riccardi F \\ Department of Pediatric Hematology Oncology, Gaslini \\ Children's Hospital, Italy \\ Correspondence: Department of Pediatric Hematology \\ Oncology, Gaslini Children's Hospital, Italy, \\ Email danielacaprino@gaslini.org
}

Received: February 17, 2017| Published: March 07, 2017

siblings experience a loss of family life, but they also had a diminished sense of self and importance within the family.

While parents appear to notice that their healthy children complain more about aches and pains, they often have little energy to attend to their needs.

Communication with siblings is important over the course of the illness and beyond. They need information about the diagnosis and therapy, as well the possibility to talk about their emotion that arise from the impact with the illness an their life and the style of adjustment. ${ }^{19,20}$

Psychosocial providers should work with the healthcare team and parents to facilitate their communication with siblings which should be updated regularly and provided with information about the disease, treatment and physical changes that may occur (eg. why and how hair loss happens) in a developmentally appropriate manner. As a matter of fact, siblings who are not involved in the care of their ill brother or sister can experience an increasing distress and feelings of helplessness with respect to their sibling's symptoms. Considering the relationship between brothers and sisters it is more easy to understand the feel of isolation, loneliness, and sometime jalousie and anger that could related not only at the period of the therapy but can be experienced also later during the years.

We report some experience in psychotherapy with siblings.

\section{Story I}

When the death for cancer is traumatic and fast, siblings don't have time to adapt to changes. Suddenly, their daily life is upset: their brother or sister is taken to hospital and healthy children, often, do not understand what is going. Kids do not understand their emotions and anxiety can increase. If the death of the brother is unexpected or his conditions are too severe to be cured, often parents do not have enough time to speak with their son and to prepare them.

L. is a boy of 6years-old. His older brother died of leukemia after only three days from diagnosis for complications due to therapies. 
His parents didn't have enough time to explain to him the events that occurred from the last time he saw his brother alive. After the funeral, his mother asked to psychological service to assess her son because of the loss. During the first three months, L. always drew his brother and spoke of him as he was alive. Often he said that at the end of the therapeutic session he would come back home to play with his brother. L. was coping with grief, using defence mechanism that keep away the loss from him: fantasy was mingling with reality. The focus of psychological work, trough weekly session, was to bring, gradually, the child to adhere to reality, facing the loss of his brother.

\section{Story 2}

$\mathrm{R}$ 's brother was affected by neuroblastoma, diagnosed at the age of 15 months.

The mother asks for a psychological support because she saw her healthy son sad, lonely and sometime aggressive towards his sick brother. He, because of the age, was not involved in the care of the sick brother and frequently entrusted to the care of an aunt who lives near the family. His older cousins told him the first time, ridiculing that his brother will die. Psychotherapy begins about a month before the death of the sick sibling, with a session per week. The first objective was to make him aware that the meeting time and the space were just for him. In that period he was able to speak about the death of his brother and about the meaning "to go to heaven" and he internalized the concept of the non-return. In this period he makes with buildings a transparent prison in which puts all the characters he used in his play, when I asked why a prison, he answered that it is a place from where you cannot come back The following months, after the dead of his little brother, the work was focused towards the elaboration of guilt linked unconscious wish his brother death and the anger that rises from the unbearable emotive situation.

Our experience shows that all the medical staff should provide helpful psychological support and adjustment to the siblings of children with cancer, under the supervision of the psychologist caring for the adjustment of the whole family. Siblings of a very sick child need to be included in the family global care by the whole staff. It is important to use a family centered approach in order to avoid a lack of adjustment and coping, post-traumatic stress, and the onset of side effects linked to misunderstood psychological distress.

\section{Acknowledgments}

None.

\section{Conflicts of interest}

Author declares there are no conflicts of interest.

\section{Funding}

None.

\section{References}

1. Peek G, Melnyk BM. Coping interventions for parents of children newly diagnosed with cancer: an evidence review with implications for clinical practice and future research. Pediatr Nurs. 2010;36(6):306-313.
2. Fletcher PC. My child has cancer: the costs of mothers' experiences of having a child with pediatric cancer. Issues Compr Peditr Nurs. 2010;33(3):164-184.

3. Fletcher PC, Schneider MA, Harry RJ. How do I cope? Factors affecting mothers' abilities to cope with pediatric cancer. J Pediatr Oncol Nurs. 2010;27(5):285-298.

4. Jones BL, Pelletier W, Decker C, et al. Fathers of children with cancer: A descriptive synthesis of the literature. Soc Work Health Care. 2010;49(5):458-493.

5. Da Silva FM, Jacob E, Nascimento LC. Impact of childhood cancer on parents' relationships: an integrative review. J Nurs Scholarsh. 2010;42(3):250-261.

6. Askins MA, Moore BD. Psychosocial support of the pediatric cancer patient: lessons learned over the past 50 years. Curr Oncol Rep. 2008;10(6):469-476.

7. Marcus J. Psychosocial Issues in Pediatric Oncology. Ochsner J. 2012;12(3):211-215.

8. Long KA, Marsland AL. Family adjustment to childhood cancer: a systematic review. Clin Child Fam Psychol Rev. 2011;14(1):57-88.

9. Wijnberg-Williams BJ, Kamps WA, Klip EC, Psychological adjustment of parents of pediatric cancer patients revisited: Five years later. Psychooncology. 2006; 15(1):1-8.

10. Yaluga I, Tufanb AE, Doksatc K, et al. Post-traumatic stress disorder and posttraumatic stress symptoms in parents of children with cancer: A review. Neurology Psychiatry Brain Research. 2011;17(1):27-31.

11. Alderfer MA, Long KA, Lown EA, et al. Psychosocial adjustment of siblings of children with cancer: a systematic review. Psychooncology. 2009;19(8):789-805.

12. Gerhardt CA, Lehmann V, Long KA, et al. Supporting Siblings as a Standard of Care in Pediatric Oncology. Pediatr Blood Cancer. 2015;62(Suppl 5):S750-S804.

13. McGrath P. Findings of the impact of treatment for childhood acute lymphoblastic leukaemia on family relationships. Child and Family Social Work. 2001;6(3):229-237.

14. Patterson JM, Holm KE, Gurney JG. The impact of childhood cancer on the family: A qualitative analysis of strains, resources, and coping behaviors. Psychooncology. 2004; 13(6):390-407.

15. Nolbris M, Enskar K, Hellstrom A. Experience of siblings of children treated for cancer. Eur J Oncol Nurs. 2007;11(2):106-112.

16. Woodgate RL. Siblings experiences with childhood cancer: a different way of being in the family. Cancer Nurs. 2006;29(5):406-414.

17. Houtzager BA, Grootenhuis MA, Caron, et al. Quality of life and psychological adaptation in siblings of paediatric cancer patients, 2 years after diagnosis. Psychooncology. 2004;13(8):499-511.

18. Barrera M, Chung JYY, Greenberg M, et al. Preliminary investigation of a group intervention for siblings of pediatric cancer patients. Children's Health Care. 2002;31(2):131-142.

19. Patterson P, Millar B, Visser A. The development of an instrument to assess the unmet needs of young people who have a sibling with cancer: Piloting the Sibling Cancer Needs Instrument (SCNI). J Pediatr Oncol Nurs. 2011;28(1):16-26.

20. Von Essen L, Enskar K. Important aspects of care and assistance for siblings of children treated for cancer. Cancer Nurs. 2003;26(3):203-210. 